\title{
Factors explaining variance in perceived pain in women with fibromyalgia
}

\author{
Eva Albertsen Malt*1, Snorri Olafsson², Anders Lund*1 and Holger Ursin ${ }^{3}$
}

Address: ${ }^{1}$ Department of Psychiatry, University of Bergen Haukeland University Hospital, N-5022 Bergen, Norway, ${ }^{2}$ Department of Internal Medicine, University of Bergen Haukeland University Hospital, N-5022 Bergen, Norway and ${ }^{3}$ Department of Biological And Medical Psychology, Division of Physiological Psychology University of Bergen, N-5022 Bergen, Norway

E-mail: Eva Malt* - eva.albertsen@psych.uib.no; Snorri Olafsson - olafsson@online.no; Anders Lund* - anders.lund@psyk.uib.no; Holger Ursin - Holger.Ursin@psych.uib.no

${ }^{*}$ Corresponding authors

Published: 25 April 2002

BMC Musculoskeletal Disorders 2002, 3:12
Received: 29 January 2002

Accepted: 25 April 2002

This article is available from: http://www.biomedcentral.com/I47I-2474/3/12

(C) 2002 Malt et al; licensee BioMed Central Ltd. Verbatim copying and redistribution of this article are permitted in any medium for any purpose, provided this notice is preserved along with the article's original URL.

\begin{abstract}
Background: We hypothesized that a substantial proportion of the subjectively experienced variance in pain in fibromyalgia patients would be explained by psychological factors alone, but that a combined model, including neuroendocrine and autonomic factors, would give the most parsimonious explanation of variance in pain.

Methods: Psychometric assessment included McGill Pain Questionnaire, General Health Questionnaire, Hospital Anxiety and Depression Rating Scale, Eysenck personality Inventory, Neuroticism and Lie subscales, Toronto Alexithymia Scale, and Multidimensional Health Locus of Control Scale and was performed in 42 female patients with fibromyalgia and 48 female age matched random sample population controls. A subgroup of the original sample (22 fibromyalgia patients and 13 controls) underwent a pharmacological challenge test with buspirone to assess autonomic and adrenocortical reactivity to serotonergic challenge.

Results: Although fibromyalgia patients scored high on neuroticism, anxiety, depression and general distress, only a minor part of variance in pain was explained by psychological factors alone. High pain score was associated with high neuroticism, low baseline cortisol level and small drop in systolic blood pressure after buspirone challenge test. This model explained $41.5 \%$ of total pain in fibromyalgia patients. In population controls, psychological factors alone were significant predictors for variance in pain.

Conclusion: Fibromyalgia patients may have reduced reactivity in the central sympathetic system or perturbations in the sympathetic-parasympathetic balance. This study shows that a biopsychosocial model, including psychological factors as well as factors related to perturbations of the autonomic nervous system and hypothalamic-pituitary-adrenal axis, is needed to explain perceived pain in fibromyalgia patients.
\end{abstract}

\section{Background}

Fibromyalgia is a chronic pain syndrome with steadily fluctuating musculo-skeletal pain as the main symptom. However, despite intensive research, the primary mecha- 
nisms underlying the etiopathogenesis of fibromyalgia remain elusive.

Some psychiatric studies suggest a relationship to anxiety disorder in a significant subgroup $[1,2]$, while other studies have found that fibromyalgia is highly associated with depressive disorders [3-7]. Many psychometric studies indicate an association between fibromyalgia, chronic distress, anxiety, depression and certain personality traits [8$15]$, although conflicting results exist $[16,17]$.

During the last decade many authors have suggested that perturbations in the autonomic nervous system is a key element in the fibromyalgia syndrome, however, contradictory results have been reported [18-23]. Also perturbations of the hypothalamic-pituitary-adrenal (HPA) axis, leading to relative insufficiency of the adrenal glands and hypocortisolism, is a neuroendocrine finding that has been described in fibromyalgia patients [24-26].

Stress, either physical, emotional or metabolic in nature, may be the essential underlying factor leading to psychiatric and somatic symptoms in fibromyalgia patients through a final common pathway [27]. The physiology of stress includes CNS and peripheral components, involving the hypothalamic-pituitary-adrenal (HPA) axis, the hypothalamic-pituitary-gonadal (HPG) axis and the autonomic (sympathetic) system.[28,29]. Stress, leading to perturbations in all these systems, may elicit pain in fibromyalgia patients [30].

Although a vast literature concerning etiopathogenetic factors in the fibromyalgia syndrome exists, we have found no published studies focusing upon which of all these factors that are most important to explain the ever changing and troublesome pain in these patients. This is a clinical important and meaningful question, as knowledge about factors influencing variance in pain is essential in the search for more efficacious pain treatment for fibromyalgia patients. To clarify this question, we assessed pain, psychiatric symptoms and personality factors in patients with fibromyalgia and population based controls. We also used a psychopharmacological challenge test to assess autonomic and adrenocortical cortisol responsiveness. We hypothesized that a substantial proportion of the subjectively experienced variance in pain in fibromyalgia patients would be explained by psychological factors alone, but that a combined model also including neuroendocrine and autonomic factors as a base of the symptomatology would give the most likely explanation of variance in pain.

\section{Materials and methods Subjects Sample I}

Caucasian female fibromyalgia patients fulfilling the ACR diagnostic criteria for fibromyalgia [31] were randomly selected from the Outpatient clinic of the Rheumatological department, Haukeland University Hospital. Fortytwo female patients with mean age 44 years (range 29-63) were included.

The control group was population-based and consisted of age-matched Caucasian women living in the city of Bergen recruited from the National Register by a randomised computer procedure. Mean age for the 48 controls was 46 years (range 23-68).

\section{Sample II}

All subjects not using any psychoactive, anti-inflammatory or antihistaminic drugs on daily basis who were included sample I, were invited to take part in the further study. Twenty-two women with fibromyalgia (mean age 45 years, range 29-63), and 14 female controls (mean age 43 years, range 30-65) accepted and were included.

\section{General assessment}

All subjects underwent a detailed and comprehensive clinical physical examination with registration of demographic and general medical data. No significant group differences were found in age or total family monthly income. Fibromyalgia patients had on average 11 years of education, while control subjects had 13 years $(\mathrm{p}=0.018)$.

\section{Pain assessment}

Pain was assessed by the Norwegian version of the MPQ [32]. The Norwegian version has three main scales: sensoric pain, affective pain and evaluative pain. Sensoric pain is defined as the sum score of 12 subscales on different sensoric aspects of pain. Affective pain is the sum score of the 5 word groups describing affective aspects of pain. One word group gives the score for evaluative pain. Total pain is the sum score of sensoric, affective and evaluative pain. One fibromyalgia patient and one control did not complete the questionnaire.

\section{Psychometric assessment}

The patients filled in a package of questionnaires. General Health Questionnaire 30-item version (GHQ-30) assesses the presence of distress and overall well-being [33]. Sum score was calculated by the Likert method (0-1-2-3). Hospital Anxiety and Depression scale (HAD-A and HAD-D) is constructed to measure psychological (psychic) symptoms of anxiety and depression in a medically ill population [34]. 
The neuroticism scale of the Eysenck Personality Questionnaire (EPQ-N) assesses general tendency to over-responsiveness or over-reactivity (neuroticism) [35]. The typical high EPQ-N scorer is an anxious, worrying individual, moody and frequently depressed. She is likely to sleep badly, and to suffer from various psychosomatic disorders. High EPQ-N-scores have been reported among patients with fibromyalgia. The lie scale of the Eysenck Personality Questionnaire (EPQ-L) assesses a tendency towards social conformity and a tendency to give only the answers the person supposes are "correct". Very high scores may be associated with actual lying.

Alexithymia was measured by the 26 -item version of Toronto Alexithymia Scale (TAS) [36]. Alexithymia is a multidimensional construct defined by a difficulty in identifying and describing feelings, a difficulty in distinguishing between feelings and bodily sensations, a paucity of fantasies and a preoccupation with external events. Alexithymia has been proposed to increase the risk for functional syndromes.

Multi Dimensional Health Locus of Control Scale (MHLCS) is an ordinal scale with three subscales of 6 items each (scoring 0-6). MHLCS measures how the subjects evaluated the possibility to have control of their own health [37]. The Internal control score is a measure of the individuals' own perceived control of their health. Chance score measures a tendency to perceive health as an outcome of luck or fate. External control score is a measure of the individuals' tendency to expect outcome to be directed by powerful others. In general terms, internal locus of control has been found to predict better coping.

\section{Buspirone challenge test}

A buspirone challenge test was performed to assess autonomic and adrenocortical responsiveness in the subjects. Buspirone is a well-known and safe azapiron, which produces a fall in blood pressure. This effect is at least partly due to inhibition of sympathoexcitatory neurons located in the rostral ventrolateral medulla [38]. However, buspirone may also decreases blood pressure through mechanisms associated with parasympathetic activation).)[39]. In addition, buspirone induces plasma adrenocorticotropic hormone (ACTH) and cortisol release [40].

All the premenopausal women were tested within the first two weeks of the menstrual cycle, i.e. in the follicular phase. Buspirone tests began at 8.30 a.m. after an overnight fast. A venous cannula was inserted, and after 15 minutes rest a blood sample was taken for baseline determinations of plasma cortisol. At 9 a.m. $60 \mathrm{mg}$ of oral buspirone in special pharmacy-prepared gelatine-containing capsules was administered. Blood pressure and venous samples were drawn after 60, 90, and 150 minutes. The time points were selected after a review of the literature which showed these time points to be the most adequate for measurement of blood pressure and hormonal responses to buspirone [41-43]. The subjects rested semisupine throughout the blood-sampling period and were not allowed to sleep.

Venous samples were taken into tubes and centrifuged within 4 hours. Plasma was stored at $-80^{\circ} \mathrm{C}$ until assay.

\section{Statistical analysis}

The statistical analyses were conducted by the SPSS-PC statistical package, version 9.0 (SPSS 1999). Mean differences in variables were assessed by one-way analyses of variance. Correlation analyses were performed between pain variables and psychological and variables derived from the buspirone challenge test. Linear regression analyses with stepwise backward procedures were performed to find the model giving the most parsimonious explanation of the variance in pain. In the large sample, all psychological variables were entered into the regression analysis. Psychological factors that contributed significantly to explained variance in pain in fibromyalgia patients, were entered together with buspirone challenge test variables in the regression analysis from the limited sample.

\section{Ethics}

All subjects were thoroughly informed by personal instruction and a written informed consent was obtained at inclusion. The Regional ethics committee and The Norwegian Data Inspectorate accepted the study. The study was performed in accordance with the Helsinki declaration.

\section{Results \\ Pain}

As expected, fibromyalgia patients had higher scores than controls on all pain scales (Table 1). Scores for sensoric, affective and evaluative pain were significantly inter-correlated in both groups with correlation coefficients between 0.41 and 0.91 .

\section{Psychological variables}

Fibromyalgia patients scored higher than controls on anxiety (HAD-A), depression (HAD-D), general distress (GHQ-30) and neuroticism (EPQ-N). The MHLCS factor "Chance" was higher, and "Internal" was lower in the patient group than in the control group (Table 2).

As expected, psychological symptom scores on HAD-A, HAD-D and GHQ were highly inter-correlated ( $\mathrm{r}>0.60, \mathrm{p}$ $<0.001$ ) and correlated also highly ( $\mathrm{r}>0.50, \mathrm{p}<0.01$ ) with EPQ-N and alexithymia (TAS) scores in both groups. 
Table I: Pain in female patients with fibromyalgia and female population controls: mean scores and $95 \%$ confidence intervals

\begin{tabular}{lllll}
\hline Mc Gill Pain Questionnaire & Fibromyalgia N = 42 & Controls N = 48 & ANOVA F-value & Probability $\mathbf{P}^{*}$ \\
\hline & & & & \\
Evaluative pain & $4.7(3.8-5.5)$ & $2.5(1.7-3.2)$ & 15.26 & $<0.001$ \\
Affective pain & $19.1(16.1-22.1)$ & $7.3(4.3-10.4)$ & $30-73$ & $<0.001$ \\
Sensoric pain & $38.7(33.0-44.3)$ & $17.2(11.8-22.6)$ & 30.50 & $<0.001$ \\
Total pain & $62.4(54.0-70.8)$ & $27.0(18.4-35.6)$ & 34.61 & $<0.001$
\end{tabular}

Table 2: Psychological variables in female patients with fibromyalgia and female population controls: mean scores with $95 \%$ confidence intervals

$$
\text { Fibromyalgia }(\mathbf{N}=42) \quad \text { Controls }(\mathrm{N}=48) \quad \text { ANOVA F-value } \quad \text { P-value }
$$

$\begin{array}{lllll}\text { Psychological symptoms } & & & \\ \text { HAD-A } & 6.2(5.0-7.4) & 4.4(3.5-5.4) & 5.4 & 0.02 \\ \text { HAD-D } & 4.9(3.7-6.0) & 2.3(1.5-3.0) & 15.5 & <0.00 \text { I } \\ \text { GHQ-30 likert } & 33.6(29-28) & 24.1(21-27) & 14.2 & <0.001 \\ \text { Personality } & & & & 0.02 \\ \text { EPQ-N } & 10.1(8.5-11.6) & 7.6(6.1-9.0) & 5.5 & 0.69 \\ \text { EPQ-L } & 9.9(8.7-11.0) & 9.6(8.7-10.4) & 0.2 & 0.21 \\ \text { TAS } & 67.7(65-71) & 64.9(62-68) & 1.6 & 0.004 \\ \text { MHLC } & & & & 0.02 \\ \text { Internal } & 20.2(18.5-22.0) & 23.8(22.2-25.3) & 9.0 & 0.60 \\ \text { Chance } & 16.4(14.8-18.0) & 13.9(12.6-15.2) & 6.2 & 0.3 \\ \text { External } & 15.4(13.7-17.1) & 16.0(15.0-17.4) & & \end{array}$

EPQ-N: Eysenck personality Questionnaire, Neuroticism scale, EPQ-L: Eysenck Personality Questionnaire, Lie scale, TAS: Toronto Alexithymia Scale, MHLCS: Multidimensional Health Locus of Control Scale, HAD-A and HAD-D: Hospital Anxiety and Depression Scale, GHQ: General Health Questionnaire, FI: Defensive hostility, F2: Instrumental mastery-oriented Coping, F3: Cognitive defence, F4: Emotional focused coping

In fibromyalgia patients, sensoric, affective and total pain correlated significantly with EPQ-N $(r=0.31-0.34, \mathrm{p}=$ $0.03-0.05)$, and affective pain correlated significantly with TAS $(r=0.32, p=0.04)$. In controls, sensoric, affective and total pain scores correlated positively with HAD$\mathrm{A}(\mathrm{r}=0.30, \mathrm{p}=0.03)$, HAD-D $(\mathrm{r}=0.44, \mathrm{p}=0.002)$, GHQ $(\mathrm{r}=0.46, \mathrm{p}=0.001)$, EPQ-N $(\mathrm{r}=0.40, \mathrm{p}=0.004)$ and negatively with MHLCS "Internal" $(\mathrm{r}=-0.45, \mathrm{p}=0.002)$.

\section{Buspirone test}

No significant group differences were seen in baseline cortisol level or in baseline systolic or diastolic blood pressure. Buspirone produced a significant time-dependent increase in plasma cortisol and a significant fall in systolic and diastolic blood pressure with no significant group differences. In fibromyalgia patients, high pain scores (sensoric, affective and total) were significantly correlated with low baseline cortisol (Table 3). A consistent pattern of negative correlations between pain scores and cortisol response to buspirone was also seen. These correlations did not reach statistical significance however $\left(\mathrm{r}_{\max }=\right.$ $0.37, \mathrm{p}=0.09$ ). Pain scores were also significantly correlated with drop in systolic and diastolic blood pressure (high pain, low drop in blood pressure, Table 3). In controls, affective pain score was significantly correlated $(\mathrm{r}=$ 0.56, $\mathrm{p}=0.04$ ) with drop in systolic, but not diastolic, blood pressure after buspirone. However, on the contrary to what was found in fibromyalgia patients, high affective pain score was associated with a large drop in systolic blood pressure.

\section{Predictors of pain}

In the total sample, only a small proportion of variance in pain could be explained by variables related to personality and psychological symptoms in the 42 fibromyalgia patients. The best model consisted of the variables EPQ-N and EPQ-L, which explained $0 \%$ of the variance in evaluative pain, $12.6 \%$ of variance in affective pain, $13.5 \%$ of variance in sensoric pain and $15.7 \%$ of variance in total pain. 
Table 3: Correlations between buspirone challenge test variables and sensoric pain score in female fibromyalgia patients and female population controls.

\begin{tabular}{|c|c|c|}
\hline & $\begin{array}{l}\text { Fibromyalgia } \\
(N=22)\end{array}$ & $\begin{array}{l}\text { Controls } \\
(N=13)\end{array}$ \\
\hline Buspirone test variable & $\begin{array}{l}\text { Correlation with } \\
\text { sensoric pain }\end{array}$ & $\begin{array}{l}\text { Correlation with } \\
\text { sensoric pain }\end{array}$ \\
\hline Baseline cortisol & $-0.43^{*}(p=0.04)$ & $0.15(p=0.61)$ \\
\hline$\Delta$ Cortisol & $-0.31(p=0.15)$ & $0.37(p=0.22)$ \\
\hline Baseline systolic blood pressure & $-0.33(p=0.14)$ & $0.43(p=0.13)$ \\
\hline$\Delta$ Systolic blood pressure & $0.50^{*}(p=0.02)$ & $-0.31(p=0.28)$ \\
\hline $\begin{array}{l}\text { Baseline diastolic blood pres- } \\
\text { sure }\end{array}$ & $-0.26(p=0.24)$ & $0.28(p=0.33)$ \\
\hline$\Delta$ Diastolic blood pressure & $0.50^{*}(p=0.02)$ & $0.00(p=1.00)$ \\
\hline
\end{tabular}

$\Delta=$ Level after 90 minutes-baseline level High pain scores are associated with a small drop in blood pressure ( $\Delta$ systolic blood pressure) after buspirone in fibromyalgia patients. A smaller drop in blood pressure after buspirone gives a smaller negative $\Delta$ value, and hence the seen positive correlation.

A larger proportion of variance in pain was explained by psychological variables in the 48 control subjects. A model consisting of the variables Internal and Chance health locus of control and total GHQ score explained $21.6 \%$ of variance in evaluative pain, $32.6 \%$ of variance in affective pain, $28.0 \%$ of variance in sensoric pain and $32.5 \%$ of variance in total pain.

In the subjects who also performed the buspirone test, a model consisting of EPQ-N, baseline cortisol level and change in systolic blood pressure explained $41.5 \%$ of total pain in fibromyalgia patients. High pain score was associated with high EPQ-N, low baseline cortisol level and small drop in systolic blood pressure after buspirone challenge test (Table 4). In controls, EPQ-N was the only significant predictor for variance in sensoric- and total pain.

\section{Discussion}

The main finding in this study is that a biopsychosocial model including psychological factors as well as factors related to perturbation of the autonomic nervous system and the HPA-axis explained a substantial part of variance of pain in the fibromyalgia patients.

When only personality factors and psychological distress was taken into account, we found a more limited impact of personality factors and psychological distress on pain severity than what has been reported in some previous studies $[8,9,44,45]$. A possible explanation for this could be that our fibromyalgia group consisted of extreme cases with high scores on psychopathology and pain with small inter-individual differences. However, this did not seem to be case. Even though there were significant differences in mean scores between patients and controls for some of the psychological variables, the mean scores in the fibromyalgia group correspond more to "moderately high normal scores " than to scores from a psychiatrically ill population.

Some authors have claimed that the personality trait alexithymia, "no words for feelings" are common in fibromyalgia patients [46,47]. This was not confirmed in our study, as no differences were seen in alexithymia scores. However, a high correlation was found between alexithymia scores and scores for anxiety, depression and neuroticism, which may indicate that alexithymia scores may be associated with psychological distress. Also previous studies have showed a strong association between alexithymia and depression and a general lack of absolute stability for the construct).)[48,49].

Fibromyalgia patients scored moderately lower on internal health locus of control and higher on chance health locus of control than control subjects. The cognitive interpretation of this pattern could be something like: "Whatever I do, my illness just go on". The same pattern has been identified as being associated with reduced likelihood for engaging in healthy behaviour in young adults [50], but could in our opinion also be interpreted as an effect of chronic illness in the fibromyalgia patient sample.

The most powerful predictor for increased sensoric pain in fibromyalgia patients was a reduced drop in systolic blood pressure after buspirone challenge. One possible explanation for this finding is that fibromyalgia patients display perturbations in central sympathetic system with reduced reactivity, which might be due to reduced sensitivity of 5$\mathrm{HT}_{1 \mathrm{~A}}$ receptors on sympathoexcitatory neurons in the rostral ventrolateral medulla. However, perturbations in the sympathetic-parasympathetic balance in fibromyalgia patients could also explain the results.

Our finding corresponds to previous findings suggesting alterations in autonomic regulation in fibromyalgia patients. Neuropeptide $\mathrm{Y}$, which co-exists with norepinephrine in the sympathetic nervous system and may represent the sympathetic-neuronal output, has been found to be elevated in fibromyalgia patients [18]. Also altered modulation of the sympathetic nervous system with deranged sympathetic response to orthostatic stress has previously been found in this patient group $[21,22]$.

Studies have provided convincing evidence that the adrenal gland is hypoactive in some stress-related states as posttraumatic stress disorder, in healthy individuals living under conditions of chronic stress as well as in patients with several bodily disorders including chronic fatigue 
Table 4: Explained variance in pain by (backward) regression analysis in femalepatients with fibromyalgia and female controls

\begin{tabular}{|c|c|c|c|c|c|c|c|}
\hline & & Fibron & $v=22)$ & & Contro & & \\
\hline Pain & Model & Adj. $r^{2}$ & t-score & $\mathrm{p}$-value & Adj. $r^{2}$ & t-score & $\mathrm{p}$-value \\
\hline Evaluative & Model & 0.00 & & & 0.00 & & \\
\hline Affective & Model & 0.38 & & 0.014 & & & \\
\hline & EPQ-N & & 2.69 & 0.015 & & & \\
\hline & Baseline cortisol & & -2.72 & 0.014 & & & \\
\hline & $\Delta$ systBT & & 2.04 & 0.057 & 0.36 & 2.76 & 0.019 \\
\hline Sensoric & Model & 0.47 & & 0.004 & & & \\
\hline & EPQ-N & & 2.32 & 0.033 & 0.49 & 3.59 & 0.004 \\
\hline & Baseline cortisol & & -2.56 & 0.020 & & & \\
\hline & $\Delta$ cortisol & & -1.74 & 0.099 & & & \\
\hline & $\Delta$ systBT & & 3.00 & 0.008 & & & \\
\hline Total & Model & 0.42 & & 0.005 & & & \\
\hline & EPQ-N & & 2.36 & 0.030 & 0.36 & 7.68 & 0.018 \\
\hline & Baseline cortisol & & -2.68 & 0.015 & & & \\
\hline & $\Delta$ systBT & & 2.79 & 0.012 & & & \\
\hline
\end{tabular}

Adj. $r^{2}$ : adjusted $r^{2}, \Delta$ systBT: systolic blood pressure after 90 minutes - baseline systolic blood pressure, $\Delta$ cortisol: cortisol level after 90 minutes - baseline cortisol

syndrome, fibromyalgia, other somatoform disorders, rheumatoid arthritis, and asthma [24,25,51]. It has been hypothesized that a persistent lack of cortisol availability in traumatized or chronically stressed individuals may promote an increased vulnerability for the development of stress-related bodily disorders [51].

Our results partly confirm these previous results. Although there were no mean differences in baseline cortisol between fibromyalgia patients and control subjects, a negative association was found between pain and baseline cortisol. A trend was seen in the regression analysis between a small cortisol response to buspirone challenge and increased pain, but the cortisol responsiveness to serotonergic challenge only explained a minor and nonsignificant part of variance in pain. However, our methodology does not allow us to assess the relative importance of sympathetic dysregulation and relative adrenal insufficiency as cortisol and blood pressure responses to buspirone may not be truly independent variables. Corticosteroids may influence sympathetic neuronal excitability, and activity in the sympatho-adrenal system may influence cortisol secretion $[52,53]$.
In controls, a different pattern was seen than in fibromyalgia patients. Psychological distress was strongly associated with perceived pain, and only affective pain was found to be associated with autonomic reactivity. Our finding of a correlation between high drop in blood pressure and high affective pain may indicate an association between affective pain and high sympathetic reactivity in population controls. However, the small sample size implicates cautiousness in the interpretation of the results.

Some methodological weaknesses are present in this study. Pain and other symptoms in fibromyalgia patients may vary through the menstrual cycle [54]. However, we were not able to control for this in our study. Buspirone has multiple pharmacological actions and may not be an ideal drug for pharmacological challenge, but was chosen because of its previous frequent use and known safety in human neuroendocrine studies. It is recognized that the first pass effect is extensive, and the major metabolite 1-(2 pyrimdinyl) piperazine (1-PP) acts as a $\alpha_{2}$ adrenoceptor antagonist. This may interfere with the interpretation of the results on a receptor level, but it has no impact on our main conclusions. In this study we were not able to measure plasma levels of buspirone or its metabolites, and 
pharmacokinetic differences due to for instance differences in absorption between groups cannot be excluded. The relatively small sample size may also have lead to type two errors.

\section{Conclusions}

This study confirms that a biopsychosocial model is needed to explain variance in pain in fibromyalgia patients. Personality traits related to over-reactivity or over-responsiveness (neuroticism) and social conformity as well as factors related to perturbation of the autonomic nervous system and the HPA-axis explained a substantial part of variance of pain in the fibromyalgia patients. Neuroticism and psychological distress also were good predictors of variance in pain in population controls.

\section{Competing interests}

None declared.

\section{Authors' contributions}

Author 1 EAM participated in the design of the study, carried out the psychometric testing and the buspirone challenge test, performed the statistical analysis and drafted the manuscript. Author 2 SO participated in the design of the study and in the administration of the buspirone challenge test. Author $3 \mathrm{AL}$ participated in the design of the study. Author 4 HU participated in the design and coordination of the study.

\section{Acknowledgments}

This study was supported by grants from the University of Bergen. We are grateful to colleges who commented on the manuscript and to the subjects of the study for their time and patience.

\section{References}

I. Malt EA, Berle J, Olafsson S, Lund A, Ursin H: Fibromyalgia is associated with panic disorder and functional dyspepsia with mood disorders. A study of women with random sample population controls. J Psychosom Res 2000, 49:285-289

2. Tanum L, Malt UF: Sodium lactate infusion in fibromyalgia patients. Biol Psychiatry 1995, 38:559-56 |

3. Martinez JE, Ferraz MB, Fontana AM, Atra E: Psychological aspects of Brazilian women with fibromyalgia Psychological aspects of Brazilian women with fibromyalgia. J Psychosom Res 1995, 39:167-174

4. Alfici S, Sigal M, Landau M: Primary fibromyalgia syndrome - a variant of depressive disorder? Psychother Psychosom 1989, $51:|56-16|$

5. Kirmayer LJ, Robbins JM, Kapusta MA: Somatization and depression in fibromyalgia syndrome. Am J Psychiatry 1988, I 45:950-954

6. Epstein SA, Kay G, Clauw D, Heaton R, Klein D, Krupp L, et al: Psychiatric disorders in patients with fibromyalgia. A multicenter investigation. Psychosomatics 1999, 40:57-63

7. Hudson JI, Goldenberg DL, Pope HG Jr, Keck PE Jr, Schlesinger L: Comorbidity of fibromyalgia with medical and psychiatric disorders. Am J Med 1992, 92:363-367

8. McBeth J, Macfarlane GJ, Benjamin S, Morris S, Silman Al: The association between tender points, psychological distress, and adverse childhood experiences: a community-based study. Arthritis Rheum 1999, 42: 1397-I404

9. Walter $B$, Vaitl D, Frank R: Affective distress in fibromyalgia syndrome is associated with pain severity. Z Rheumatol 1998, 57(Suppl 2): 101-104
10. Goldenberg DL: Psychologic studies in fibrositis. Am J Med I 986, $81: 67-70$

II. Walker EA, Keegan D, Gardner G, Sullivan M, Katon WJ, Bernstein $D$ : Psychosocial factors in fibromyalgia compared with rheumatoid arthritis: I. Psychiatric diagnoses and functional disability. Psychosom Med 1997, 59:565-57I

12. Ahles TA, Yunus MB, Riley SD, Bradley JM, Masi AT: Psychological factors associated with primary fibromyalgia syndrome. Arthritis Rheum 1984, 27: I I0I-II06

13. Anderberg UM, Forsgren T, Ekselius L, Marteinsdottir I, Hallman J: Personality traits on the basis of the Temperament and Character Inventory in female fibromyalgia syndrome patients. Nord J Psychiatry 1999, 53:353-359

14. Ekselius L, Bentsson A, von Knorring L: Personality traits as determined by means of the Karolinska scales of personality in patients with fibromyalgia. J Musculoskel Pain 1998, 6:35-49

15. Netter $P$, Hennig J: The fibromyalgia syndrome as a manifestation of neuroticism? Z Rheumatol 1998, 57(Suppl 2): 105-108

16. Ahles TA, Khan SA, Yunus MB, Spiegel DA, Masi AT: Psychiatric status of patients with primary fibromyalgia, patients with rheumatoid arthritis, and subjects without pain: a blind comparison of DSM-III diagnoses. Am J Psychiatry 199I, I48:172I1726

17. Spanjer ]: [Is there a characteristic personality profile in patients with fibromyalgia? Study of achievement motivation and coping] Is er een kenmerkende persoonlijkheidsstructuur bij fibromyalgiepatienten? Onderzoek naar prestatiemotivatie en coping. Ned Tijdschr Geneeskd 1994, I 38:2 I45-2 I49

18. Anderberg UM, Liu Z, Berglund L, Nyberg F: Elevated plasma levels of neuropeptide $\mathbf{Y}$ in female fibromyalgia patients. Eur J Pain 1999, 3:19-30

19. Cohen H, Neumann L, Kotler M, Buskila D: Autonomic nervous system derangement in fibromyalgia syndrome and related disorders. Isr Med Assoc 」 200I, 3:755-760

20. Cohen H, Neumann L, Alhosshle A, Kotler M, Abu-Shakra M, Buskila $D$ : Abnormal sympathovagal balance in men with fibromyalgia. J Rheumatol 200I, 28:58I-589

21. Martinez-Lavin M, Hermosillo AG, Mendoza C, Ortiz R, Cajigas JC, Pineda $C$, et al: Orthostatic sympathetic derangement in subjects with fibromyalgia.J Rheumatol 1997, 24:714-7/8

22. Martinez-Lavin M, Hermosillo AG, Rosas M, Soto ME: Circadian studies of autonomic nervous balance in patients with fibromyalgia: a heart rate variability analysis. Arthritis Rheum 1998, 41:1966-197|

23. Vaeroy H, Qiao ZG, Morkrid L, Forre O: Altered sympathetic nervous system response in patients with fibromyalgia (fibrositis syndrome). J Rheumatol 1989, 16: | 460-1465

24. Neeck G, Crofford LJ: Neuroendocrine perturbations in fibromyalgia and chronic fatigue syndrome. Rheum Dis Clin North Am 2000, 26:989-1002

25. Griep E-N, Boersma J-W, De Kloet E-R: Altered reactivity of the hypothalamic-pituitary-adrenal axis in the primary fibromyalgia syndrome. S Rheumatol 1993, 20:469-474

26. Crofford LJ, Pillemer SR, Kalogeras KT, Cash JM, Michelson D, Kling $M A$, et al: Hypothalamic-pituitary-adrenal axis perturbations in patients with fibromyalgia. Arthritis Rheum 1994, 37:1 583-1592

27. Crofford LJ, Demitrack MA: Evidence that abnormalities of central neurohormonal systems are key to understanding fibromyalgia and chronic fatigue syndrome. Rheum Dis Clin North Am 1996, 22:267-284

28. Pillemer SR, Bradley LA, Crofford LJ, Moldofsky H, Chrousos GP: The neuroscience and endocrinology of fibromyalgia. Arthritis Rheum 1997, 40: 1928-1939

29. Crofford $L J:$ The hypothalamic-pituitary-adrenal stress axis in fibromyalgia and chronic fatigue syndrome. $Z$ Rheumatol 1998 , 57(Suppl 2):67-7|

30. Anderberg UM: Fibromyalgia Syndrome in Women - a Stress Disorder? Neurobiological and Hormonal aspects. Uppsala University; Dissertation 1999

31. Wolfe F, Smythe HA, Yunus MB, Bennett RM, Bombardier C, Goldenberg DL, et al: The American College of Reheumatology 1990 criteria for the classification of fibromyalgia: report of the Multicenter Criteria Committee. Arthritis Rheum 1990, 33:160-172

32. Strand LI, Wisnes AR: The development of a Norwegian pain questionnaire. Pain I99I, 46:6I-66 
33. Goldberg D, Williams P: A user's guide to the General Health Questionnaire. Windsor: NFER-Nelson; 1988

34. Zigmond AS, Snaith RP: The hospital anxiety and depression scale. Acta Psychiatr Scand 1983, 67:36 I-370

35. Eysenck H, Eysenck S: The manual for the Eysenck Personality Questionnaire. London: Hodder \& Stoughton; 1975

36. Taylor G], Bagby RM, Ryan DP, et al: Criterion validity of the Toronto Alexithymia Scale. Psychosom Med 1988, 50:500-509

37. Rotter JB: Generalized expectancies for internal versus external control of reinforcement. Psychol Monogr 1966, 80:

38. Kubo T, Taguchi K, Ozaki S, Amano M, Ishizuka T: 8-OH-DPAT-induced hypotensive action and sympathoexcitatory neurons in the rostral ventrolateral medulla of the rat. Brain Res Bull 1995, 36:405-4II

39. Lechin F, Van Der Dijs B, Jara H, Orozco B, Baez S, Benaim M, Lechin $M$, Lechin $A$ : Effects of buspirone on plasma neurotransmitters in healthy subjects. J Neur Trans 1998, I05(Suppl 6-7):56I573

40. Maes M, Van Gastel A, Meltzer HY, Cosyns P, Blockx P, Desnyder R: Acute administration of buspirone increases the escape of hypothalamic-pituitary-adrenal-axis hormones from suppression by dexamethasone in depression. Psychoneuroendocrinology 1996, 21:67-81

4I. Chua A, Keating J, Hamilton D, Keeling PW, Dinan TG: Central serotonin receptors and delayed gastric emptying in non-ulcer dyspepsia. BMJ 1992, 305:280-282

42. Cowen PJ, Power AC, Ware CJ, Anderson IM: 5-HTIA receptor sensitivity in major depression. A neuroendocrine study with buspirone. Br J Psychiatry 1994, 164:372-379

43. Dinan TG, Yatham LN, Barry S, Chua A, Keeling PW: Serotonin supersensitivity: the pathophysiologic basis of non-ulcer dyspepsia? A preliminary report of buspirone/prolactin responses. Scand J Gastroenterol 1990, 25:54 I-544

44. Nyklicek I, Vingerhoets AJ: Alexithymia is associated with low tolerance to experimental painful stimulation. Pain 2000, 85:47I-475

45. Kurtze N, Gundersen KT, Svebak S: The role of anxiety and depression in fatigue and patterns of pain among subgroups of fibromyalgia patients. Br J Med Psychol I 998, 7 I(Pt 2): $185-194$

46. Brosschot JF, Aarsse HR: Restricted emotional processing and somatic attribution in fibromyalgia. Int J Psychiatry Med 200I, 3I:127-146

47. Leichner-Hennig R, Vetter GW: [Relation between pain experience and psychological markers in patients with fibrositis syndrome and patients with rheumatoid arthritis]. Z Rheumatol 1986, 45:139-145

48. Honkalampi K, Hintikka J, Tanskanen A, Lehtonen J, Viinamaki H: Depression is strongly associated with alexithymia in the general population. J Psychosom Res 2000, 48:99-104

49. Luminet $O$, Bagby RM, Taylor G]: An evaluation of the absolute and relative stability of alexithymia in patients with major depression. Psychother Psychosom 2001, 70:254-260

50. Steptoe A, Wardle J: Locus of control and health behaviour revisited: a multivariate analysis of young adults from 18 countries. Br J Psychol 200I, 92 Part 4:659-672

5I. Heim $C$, Ehlert $U$, Hellhammer $\mathrm{DH}$ : The potential role of hypocortisolism in the pathophysiology of stress-related bodily disorders. Psychoneuroendocrinology 2000, 25: I-35

52. Joels M, Hesen W, de Kloet ER: Long-term control of neuronal excitability by corticosteroid hormones. J Steroid Biochem Mol Biol 1995, 53:315-323

53. Ehrhart-Bornstein M, Bornstein SR, Gonzalez-Hernandez J, Holst JJ, Waterman MR, Scherbaum WA: Sympathoadrenal regulation of adrenocortical steroidogenesis. Endocr Res 1995, 21:13-24

54. Anderberg UM, Marteinsdottir I, Hallman J, Baeckstroem T: Variability in the cyclicity affects pain and other symptoms in female fibromyalgia syndrome patients. J Musculoskel Pain 1998, 6:5-22

\section{Pre-publication history}

The pre-publication history for this paper can be accessed here:

http://www.biomedcentral.com/1471-2474/3/12/prepub
Publish with BioMed Central and every scientist can read your work free of charge

"BioMedcentral will be the most significant development for disseminating the results of biomedical research in our lifetime." Paul Nurse, Director-General, Imperial Cancer Research Fund

Publish with BMC and your research papers will be:

- available free of charge to the entire biomedical community

- peer reviewed and published immediately upon acceptance

- cited in PubMed and archived on PubMed Central

- yours - you keep the copyright

Submit your manuscript here:

http://www.biomedcentral.com/manuscript/
BioMedcentral.com editorial@biomedcentral.com 